\title{
Acute effects of urban air pollution on respiratory health of children with and without chronic respiratory symptoms
}

Saskia C van der Zee, Gerard Hoek, H Marike Boezen, Jan P Schouten, Joop $\mathrm{H}$ van Wijnen, Bert Brunekreef

\begin{abstract}
Objectives-To investigate to what extent different components of air pollution are associated with acute respiratory health effects in children with and without chronic respiratory symptoms.

Methods-During three consecutive winters starting in 1992-3, peak expiratory flow (PEF) and respiratory symptoms were registered daily in panels of children of 7-11 years old with and without symptoms, living in urban areas with high traffic intensity in The Netherlands. Simultaneously, panels of children living in non-urban areas were studied. Daily measurements of particles with aerodynamic diameter $<10 \mu \mathrm{m} \quad\left(\mathbf{P M}_{10}\right)$, black smoke (BS), sulphate, $\mathrm{SO}_{2}$, and $\mathrm{NO}_{2}$ were performed in both areas.
\end{abstract}

Results-The contrast in particle concentrations $\left(\mathbf{P M}_{10}, \mathrm{BS}\right.$, and sulphate) between urban and non-urban areas was small, but there was more contrast in the concentrations of $\mathrm{SO}_{2}$ and $\mathrm{NO}_{2}$. In children with symptoms from both areas, significant associations were found between $\mathbf{P M}_{10}$, $B S$, and sulphate concentrations and the prevalence of symptoms of the lower respiratory tract (LRS) and decrements in PEF. Particle concentrations were also associated with use of bronchodilators in the urban areas, but not in the non-urban areas. After stratification by use of medication, stronger associations were found in children who used medication than in children who did not use medication. The magnitude of the estimated effects was in the order of a twofold increase in the use of bronchodilators, a $50 \%$ increase in LRS, and an $80 \%$ increase in decrements in PEF for a $100 \mu \mathrm{g} / \mathrm{m}^{3}$ increase in the 5 day mean $\mathbf{P M}_{10}$ concentration. In children without symptoms, significant associations were found between concentrations of $P M_{10}$ and BS and decrements in PEF in both areas, but these associations were smaller than those for children with symptoms. No associations with respiratory symptoms were found.

Conclusions-The results suggest that children with symptoms are more susceptible to the effects of particulate air pollution than children without symptoms, and that use of medication for asthma does not prevent the adverse effects of particulate air pollution in children with symptoms. (Occup Environ Med 1999;56:802-812)
Keywords: air pollution; respiratory health; chronic respiratory symptoms

Severe episodes of air pollution in winter in the past have been associated with serious health effects, such as increased hospital admissions and mortality. ${ }^{1}$ Over the past decades, concentrations of traditional winter air pollution components such as $\mathrm{SO}_{2}$ and airborne coarse particulates have decreased in the Netherlands and other European countries. This decrease can be ascribed to emission abatement measures and changes in energy production for industrial processes and space heating. Concentrations of other pollutants such as $\mathrm{NO}_{2}$ and $\mathrm{O}_{3}$ have increased during the same period, mostly due to higher intensity of motorised traffic. Motorised traffic also plays an important part in the formation of particulate air pollution, both directly and indirectly through the formation of secondary aerosols. ${ }^{2}$ Recent studies have shown that current concentrations of particulate air pollution are associated with adverse health outcomes, even at concentrations well below the 1987 World Health Organisation air quality guidelines for Europe. ${ }^{34}$

Also in The Netherlands associations were reported between low levels of winter air pollution and respiratory health among children. ${ }^{5-7}$ However, those studies have mainly been conducted in non-urban areas. It was not clear to what extent such associations would be different in urban areas where the contribution of local sources to the air pollution mixture is greater than in non-urban areas.

The uncertainties surrounding acute effects of episodes of winter smog in large urban areas led us to perform a large epidemiological winter smog study that was conducted during three consecutive winters starting in 1992-3. The study was designed to compare acute health effects of winter air pollution in selected panels of children and adults, with and without chronic respiratory symptoms, living in urban and non-urban areas. This paper describes the results for the groups of children. The results for the groups of adults will be described in a separate paper.

\section{Methods}

STUDY DESIGN

The study was carried out during three consecutive winters starting in 1992-3. During each winter, panels of children, $7-11$ years old, with and without chronic respiratory 


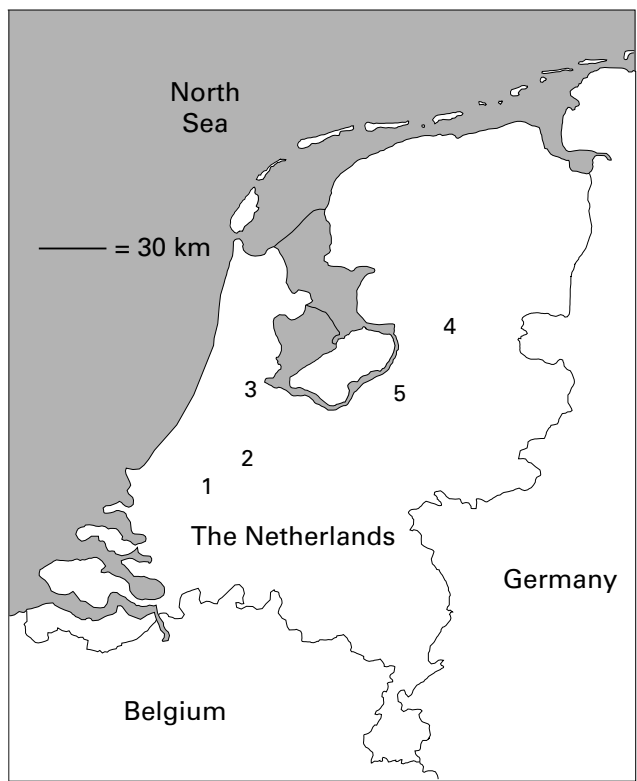

Location of the study areas during the three winters. $1=$ Rotterdam (urban area 1992-3), 2=Bodegraven / Reeuwijk (non-urban area 1992-3), 3=Amsterdam (urban area 1993-4 and 1994-5), 4=Meppel (non-urban area 1993-4), 5=Nunspeet (non-urban area 1994-5).

symptoms were selected from an urban and a non-urban area. The children were selected from the general population of children with a screening questionnaire. During the 3 month study periods daily measurements of peak expiratory flow (PEF) were made, and the occurrence of acute respiratory symptoms and use of bronchodilators was registered in a daily diary. Air pollution was monitored daily on central sites in each community.

\section{STUDY POPULATION}

Study areas chosen were: Rotterdam and Bodegraven/Reeuwijk (1992-3), Amsterdam and Meppel (1993-4), and Amsterdam and Nunspeet (1994-5). Figure 1 shows the locations of the areas. The Netherlands is a country with a very high population density. The southern, and especially the western parts, are most urbanised. The northeastern part has a relatively low population density. All major cities are located in the western part. Rotterdam is an industrialised city with about 600000 inhabitants. It is in the centre of the Rijnmond area (a conglomeration of industrial cities). Amsterdam (720 000 inhabitants) has a relatively small industrial area; local air pollution is caused primarily by emissions from motorised traffic. As well as local air pollution, transport of air pollution from other parts of the Netherlands and from other European countries contributes to the levels of air pollution in Dutch cities.

For the urban panels the objective was to select children with high exposure to air pollution related to traffic. Therefore, in both Rotterdam and Amsterdam areas in the inner city were selected with a high traffic intensity and a high population density, but with no industrial sources.

The non-urban panels were selected from communities which had no major traffic emissions, no large industrial sources, and had sufficient size to select enough children.

During the first winter (1992-3) we selected a non-urban area close to (about $30 \mathrm{~km}$ ) the urban area. During the second and third winters we selected the non-urban areas further from the urban area to try to maximise the contrast in air pollution, which was found to be small in the first winter.

Screening questionnaires were used to obtain information on chronic respiratory symptoms. The questionnaires were distributed through the schools or by mail to all children aged 7-11 years, and had to be filled out and returned by their parents. The screening questionnaire was an adapted version of questions from the World Health Organisation questionnaire for children. ${ }^{8}$ During the first winter (1992-3), a slightly different questionnaire was used. The reason for this was that during the winter of 1993-4, the study was performed in the framework of the pollution effects of asthmatic children in Europe (PEACE) study and thus the PEACE protocol was followed. ${ }^{9}$ Children were considered to have symptoms if they had a positive answer to one or more of the screening questions listed in table 1. Children without any reported symptoms on the screening questionnaire were considered not to have symptoms. Children with and without symptoms were selected randomly from those who met the selection criteria. Target panel size was 75 children for each panel, both with and without symptoms, during the winters of 1992-3 and 1993-4. During the winter of 1994-5 target panel size was 60 children with symptoms and 40 children without symptoms. The study was approved by the medical ethics committee of the Groningen University Hospital and the medical ethics committee of the Municipal Health Service in Amsterdam. Informed consent was signed by the parents of all children.

Table 1 Selection of questions from the screening questionnaire for the three winters

\begin{tabular}{|c|c|c|}
\hline & $1992-3$ & $1993-4$ and $1994-5$ \\
\hline Recent asthma & $\begin{array}{l}\text { Has your child been bothered in the past year by attacks of } \\
\text { shortness of breath with wheezing? }\end{array}$ & $\begin{array}{l}\text { Has your child been bothered in the past } 12 \text { months by attacks } \\
\text { of shortness of breath with wheezing? }\end{array}$ \\
\hline Chronic cough & $\begin{array}{l}\text { Does your child cough like this almost daily for three months } \\
\text { a year? (This question follows two other questions on cough } \\
\text { during the day or night, on most days during the autumn } \\
\text { and winter season) }\end{array}$ & $\begin{array}{l}\text { Has your child had a dry cough at night in the past } 12 \text { months, } \\
\text { apart from coughing with a cold or chest infection? }\end{array}$ \\
\hline Doctor diagnosed asthma & Has a doctor ever said your child has asthma? & Has a doctor ever said your child has asthma? \\
\hline $\begin{array}{l}\text { Recently treated by a specialist } \\
\text { for asthma }\end{array}$ & $\begin{array}{l}\text { Has your child been treated for asthma by a specialist during } \\
\text { the past year? }\end{array}$ & - \\
\hline Recent wheeze & - & $\begin{array}{l}\text { Has your child been bothered in the past } 12 \text { months by a } \\
\text { wheezy chest, apart from a cold? }\end{array}$ \\
\hline
\end{tabular}


EXPOSURE ASSESSMENT

Twenty four hour measurements of particles with aerodynamic diameter of $<10 \mu \mathrm{m}\left(\mathrm{PM}_{10}\right)$ and black smoke (BS) were made at fixed sites in both the urban and non-urban areas. Also, 24 hour measurements of non-organic secondary aerosols (sulphate, nitrate, and ammonium) and aerosol acidity were made. Measurements were from 1500 on one day to 1500 on the next. The particle measurement sites were chosen so that they were close to the residences of the participating children, and not strongly influenced by local sources such as traffic and industry in the direct vicinity (background sites). Information about the ambient concentrations of $\mathrm{SO}_{2}$ and $\mathrm{NO}_{2}$ in Rotterdam was obtained from a city background station of the National Air Quality Monitoring Network, operated by the National Institute of Public Health and Environmental Protection. In Amsterdam, information was obtained from a city background station of the Air Quality Monitoring Network operated by the Environmental Research Institute of the City of Amsterdam. Data for the non-urban areas were obtained from the nearest measurement sites of the National Air Quality Monitoring Network, located in Zegveld, Witteveen, and Lelystad during the three consecutive winters. Those measurement sites were about 10, 40, and 30 $\mathrm{km}$ away from the non-urban areas, respectively. The $\mathrm{SO}_{2}$ and $\mathrm{NO}_{2}$ concentrations were provided as 1 hour means and transformed into 24 hour average concentrations from 15001500. More information about the methods of measurement is reported elsewhere. ${ }^{10}$

Temperature was measured at 1 hourly intervals and the minimum between 1500 and 1500 was recorded. Data for the urban areas were obtained from Rotterdam and Amsterdam airports, respectively. Data for the nonurban areas in the three consecutive winters were obtained from Zegveld, Eelde, and Lelystad, 10, 40, and $30 \mathrm{~km}$ away from the non-urban areas.

Data on the weekly incidence of influenza and influenza-like illness were obtained from the Dutch Institute of Primary Health Care (NIVEL). A detailed analysis of the incidence data for the influenza-like illness relative to the health data collected in our groups will be reported elsewhere (unpublished data).

HEALTH MEASUREMENTS

During the study period, participants performed PEF measurements twice daily with Mini Wright peak flow meters, once in the morning before breakfast and once in the evening before going to bed. Subjects were instructed to perform the PEF measurements before any airway medication was taken. Every test consisted of three manoeuvres and participants were asked to note all three readings in a diary. The highest of the three PEF readings was used for analysis.

The diary was also used to register the occurrence of acute respiratory symptoms and use of medication. Symptoms included in the diary were cough, phlegm, runny or stuffed nose, woken up with breathing problems, shortness of breath, wheeze, and attacks of shortness of breath with wheeze and fever. During the winters of 1993-4 and 1994-5, the symptoms eye irritation and sore throat were included as well. Subjects were instructed to indicate whether the symptoms were absent, slight, or moderate to severe on each day. To assess use of medication, subjects had to write down the name of the medication and the number of units taken. The use of the diary and Mini Wright meter was demonstrated during a home visit in the presence of the child and at least one of the parents.

\section{DATA ANALYSIS}

All panels were analysed separately. Next, combined effect estimates were calculated for children with and without symptoms, and for urban and non-urban areas separately.

For each subject, the first 2 days of measurement were removed to eliminate a possible training effect. Subjects with missing diary information (PEF or symptoms) on $>40 \%$ of the days were removed from the dataset. All statistics were analysed with SAS. ${ }^{12}$

For the analysis of PEF data, a different approach was used compared with other panel studies, including the PEACE study. ${ }^{591314}$ Those studies were focusing on population average responses, whereas our approach was focusing on the fraction of children experiencing substantial decrements in PEF. A comparison between the two approaches is described by Hoek et al. ${ }^{15}$ In short, it shows that small decrements in population mean PEF are accompanied by large increases in the fraction of children that have a substantial decrease in PEF.

For each individual child the median morning and evening PEF was calculated. Percentage morning decrements were calculated for each measurement day for each subject by subtracting the individual median of morning PEF from the morning PEF measured on that day and dividing the difference by the individual median of morning PEF. The prevalence of morning decrements larger than $10 \%$ and $20 \%$ respectively was calculated as the number of children experiencing such a decrement divided by the total number of children reporting valid PEF measurements on each day of study. The percentage evening decrements were calculated the same way.

After recoding the symptoms in the diary, $0=$ no symptom and $1=$ slight or moderate to severe symptoms, daily prevalence was calculated for each panel as the fraction of children for whom presence of a respiratory symptom was reported, with data only from those children with no missing information in the diary for each separate day. The symptoms shortness of breath, wheeze, and attacks of shortness of breath with wheeze were combined as symptoms of the lower respiratory tract (LRSs). Cough was analysed separately. Runny or stuffed nose and sore throat were combined as symptoms of the upper respiratory tract (URS). Medication use was divided into bronchodilators-such as salbutamol, fenoterol, terbutalin-maintenance medication - such as cromoglycate, theophyllin, anti-histaminica and inhaled corticosteroids- 
Table 2 Characteristics of the panels

\begin{tabular}{|c|c|c|c|c|}
\hline & \multicolumn{2}{|l|}{ Symptoms } & \multicolumn{2}{|l|}{ No symptoms } \\
\hline & Urban area & Non-urban area & Urban area & Non-urban area \\
\hline Original sample size & 193 & 203 & 196 & 203 \\
\hline Final sample size & 142 & 178 & 137 & 176 \\
\hline Winter $1992-3$ & 31 & 48 & 43 & 60 \\
\hline Winter 1993-4 & 55 & 71 & 56 & 77 \\
\hline Winter 1994-5 & 56 & 59 & 38 & 39 \\
\hline \multicolumn{5}{|c|}{ Prevalence of screened symptoms and use of medication ( $\%$ of final sample): } \\
\hline Recent wheeze & 44 & 46 & 0 & 0 \\
\hline Recent asthma & 29 & 37 & 0 & 0 \\
\hline Chronic cough & 83 & 71 & 0 & 0 \\
\hline Doctor diagnosed asthma & 26 & 38 & 0 & 0 \\
\hline Daily medication use & 16 & 24 & 0 & 0 \\
\hline \multicolumn{5}{|c|}{ Mean daily prevalence (\%) of symptoms, use of medication, PEF decrements, and mean PEFt: } \\
\hline Lower respiratory tract & 8.4 & 9.1 & 0.8 & 1.1 \\
\hline Upper respiratory tract & 37 & 35 & 21 & 23 \\
\hline Cough & 35 & 35 & 16 & 18 \\
\hline Phlegm & 15 & 19 & 7.4 & 6.3 \\
\hline Use of bronchodilator & 4.8 & 3.4 & - & - \\
\hline Use of Maintenance medication & 8.5 & 15.5 & - & - \\
\hline$>10 \%$ Decrements in evening PEF & 10.5 & 10.8 & 9.4 & 7.3 \\
\hline Mean evening PEF $(1 / \mathrm{min})$ & 329 & 329 & 346 & 358 \\
\hline
\end{tabular}

${ }^{\star}$ Smaller than original sample size because subjects with $>40 \%$ of the diary information missing were excluded.

†Pooled prevalences and PEF were calculated as the mean of the subject specific prevalences and PEF, weighted for the number of person-days that each group contributed.

and other medication, and was recoded as 0 (no use of medication) or 1 (any use of medication), for bronchodilators and maintenance medication separately. For the study reported here, only LRS, URS, cough, phlegm, and use of bronchodilators were analysed.

The explanatory variables were 24 hour mean concentration of $\mathrm{PM}_{10}, \mathrm{BS}, \mathrm{SO}_{2}, \mathrm{NO}_{2}$, sulphate, and nitrate, analysed separately. Concentration for the current day (lag 0), previous day (lag 1), 2 days before (lag 2 ), and the mean concentration of $0-4$ days before ( 5 day mean) were analysed separately.

The association between air pollution and the prevalence of decrements in PEF, symptoms, and use of bronchodilators was evaluated with logistic regression with the PROC MODEL, but under the assumption of normally distributed residuals. This was done because when a binomial distribution was assumed the residuals showed considerable underdispersion. The number of subjects reporting on each day was used for weighting, and correction for autocorrelation of residuals was made assuming a first order autoregressive structure. Minimum daily temperature, an indicator variable for day of week (school day versus weekend or holiday), time trend, and the incidence of influenza and influenza-like illness in the general population were included in the model as potential confounders. Time trend was included as a linear, quadratic, and cubic term because in most panels strong non-linear time trends were found in the prevalence of symptoms, use of medication, and decrements in PEF.

The incidence of influenza-like illness, registered by the Dutch network of sentinel stations, was included in the model with two variables representing respectively the mean incidence of 0-6 days earlier and 7-13 days earlier. A motivation of the selection of these variables, as well as an association between incidence of influenza-like illness and respiratory health in the groups will be reported elsewhere. ${ }^{11}$
Combined effect estimates were calculated for panels of children with and without symptoms, and for urban and non-urban areas separately, with the regression slopes from the panel specific logistic regression models for the three winters. Combined effect estimates were calculated as the weighted mean of the panel specific slopes, with the weights being the inverse of the group specific variances of the slopes. The SEM of the combined slope was calculated as the inverse of the square root of the sum of weights. Odds ratios (ORs) were calculated for an increase of $100 \mu \mathrm{g} / \mathrm{m}^{3}$ in $\mathrm{PM}_{10}$ concentration, an increase of $40 \mu \mathrm{g} / \mathrm{m}^{3}$ in BS, $\mathrm{SO}_{2}$ and $\mathrm{NO}_{2}$ concentration and an increase of $15 \mu \mathrm{g} / \mathrm{m}^{3}$ in sulphate concentration.

To test whether the association between air pollution and respiratory health differed significantly between urban and non-urban areas, a weighted linear regression was performed with the group specific regression slopes as the dependent variable and an indicator for area (urban $v$ non-urban area) as the independent variable. The inverse of the group specific variances of the slopes were used for weighting. The weighted regression analysis was performed for children with and without symptoms separately.

Multiple regression models including two pollutants simultaneously have been specified for the symptomatic groups, in an attempt to separate effects from specific components of the air pollution mixture. This was done for the following combinations of pollutants: $\mathrm{PM}_{10}$ and $\mathrm{SO}_{2}, \mathrm{PM}_{10}$ and $\mathrm{BS}, \mathrm{PM}_{10}$ and sulphate, and BS and sulphate. The same lags were evaluated simultaneously for both pollutants.

\section{Results}

From the 12331 screening questionnaires handed out during the three winters, 5770 $(47 \%)$ were returned. The response was slightly lower in the urban areas (42\%) than in the non-urban areas (52\%). Of the 5770 children who returned questionnaires, 931 (16\%) were eligible and willing to participate in the groups with symptoms, whereas 1198 $(21 \%)$ were eligible and willing to participate in the groups without symptoms. From the 396 children with and 399 children without symptoms that were enrolled, respectively 320 and 313 were included in the final analysis.

In table 2 some characteristics of the groups are shown. Chronic cough was the screening symptom with the highest prevalence in the groups with symptoms. The prevalence of $>10 \%$ decrements in evening PEF was on average $10.6 \%$ in the groups with symptoms and $8.3 \%$ in the groups without symptoms. Symptomatic groups had a higher prevalence of acute respiratory symptoms than groups without symptoms.

In urban groups with symptoms the prevalence of maintenance medication was almost twofold lower than in non-urban groups with symptoms ( $8.5 \%$ and $15.5 \%$, respectively). Use of bronchodilators was not reported in the panels without symptoms during the three winters. Lower respiratory symptoms (LRS) were rarely reported in the panels without 
Table 3 Air pollution, temperature, and incidence of influenza like illness

\begin{tabular}{|c|c|c|c|c|c|c|c|c|c|}
\hline & \multirow[b]{2}{*}{ Study period } & \multirow[b]{2}{*}{ Days (n) } & \multicolumn{5}{|c|}{ Median and maximum $24 \mathrm{~h}$ mean concentrations $\left(\mu \mathrm{g} / \mathrm{m}^{3}\right)$} & \multirow{2}{*}{$\begin{array}{l}\text { Minimum hourly } \\
\text { temperature ( }{ }^{\circ} \mathrm{C} \text { ) of } 24 \mathrm{~h} \\
\text { values (median (range)) }\end{array}$} & \multirow{2}{*}{$\begin{array}{l}\text { Incidence } 10 \text { 000 } \\
\text { subjects of influenza } \\
\text { like illness in previous } \\
\text { week (median (range)) }\end{array}$} \\
\hline & & & $P M_{10}$ & Black smoke & Sulphate & $\mathrm{SO}_{2}$ & $\mathrm{NO}_{2}$ & & \\
\hline \multicolumn{10}{|l|}{ 1992-3: } \\
\hline Urban & $22 / 1 / 93-19 / 4 / 93$ & 88 & $48(146)$ & $15(56)$ & $5.3(17)$ & $23(152)$ & $51(94)$ & $4.2(-2.9,9.8)$ & $37(10,67)$ \\
\hline Non-urban & $21 / 1 / 93-19 / 4 / 93$ & 89 & $35(104)$ & $10(38)$ & $5.9(15)$ & $8.9(43)$ & $33(83)$ & $2.8(-4.4,9.8)$ & $23(5,65)$ \\
\hline \multicolumn{10}{|c|}{ 1993-4: } \\
\hline Urban & $3 / 11 / 93-6 / 3 / 94$ & 124 & $37(123)$ & $12(65)$ & $2.7(24)$ & $11(34)$ & $48(76)$ & $2.7(-8.1,10.0)$ & $9(0,122)$ \\
\hline Non-urban & $17 / 11 / 93-6 / 3 / 94$ & 110 & $35(242)$ & $10(58)$ & $2.8(23)$ & $5.0(42)$ & $25(54)$ & $1.0(-10.9,9.3)$ & $3(0,56)$ \\
\hline \multicolumn{10}{|l|}{ 1994-5: } \\
\hline Urban & $25 / 11 / 94-5 / 3 / 95$ & 101 & $29(90)$ & $6.9(28)$ & $1.7(10)$ & $6.0(24)$ & $47(82)$ & $3.8(-5.0,11.5)$ & $2(0,10)$ \\
\hline Non-urban & $23 / 11 / 94-5 / 3 / 95$ & 103 & $24(97)$ & $5.8(43)$ & $1.9(18)$ & $3.6(17)$ & $22(57)$ & $3.1(-11.1,11.3)$ & $2(0,20)$ \\
\hline
\end{tabular}

symptoms; during the winters of $1992-3$ and 1994-5, the panel specific prevalences of LRS were too low to be analysed. Only during the winter of 1993-4 was the mean panel specific prevalence of LRS relatively high $(1.2 \%$ in the urban area and $2.0 \%$ in the non-urban area).

Table 3 shows the results of the air pollution measurements. The median concentrations of $\mathrm{PM}_{10}$ and BS were only slightly higher in the urban areas than in the non-urban areas. There was more contrast in the concentration of the gaseous pollutants $\mathrm{SO}_{2}$ and $\mathrm{NO}_{2}$. The median concentration of sulphate was slightly lower in the urban than in the non-urban areas. Concentrations of aerosol acidity were very low during the three winters (not shown). Only a few concentrations were above the detection limit $\left(0.10 \mu \mathrm{g} / \mathrm{m}^{3}\right)$ and therefore, concentrations of aerosol acidity were not used in further analyses.

During the winters of 1992-3 and 1993-4, episodes of air pollution occurred resulting in increased concentrations of particles in both the urban and non-urban areas. During the winter of 1994-5 no episodes of air pollution occurred as a result of mild meteorological conditions. For a more detailed description of the air pollution concentrations and episodes we refer to another paper. ${ }^{10}$

Spearman correlations between the various air pollutants and potential confounding variables were calculated separately for the urban and non-urban areas during the three winters (not shown). During the first two winters, when episodes of air pollution occurred, a high correlation $(R>0.7)$ was found between $\mathrm{PM}_{10}$ and the other indicators of particulate air pollution BS and sulphate. The correlation between $\mathrm{SO}_{2}$ and indicators of particulate air pollution varied between 0.5 and 0.8 and was slightly higher than the correlation between $\mathrm{NO}_{2}$ and indicators of particulate air pollution (except for BS). The correlation between $\mathrm{SO}_{2}$ and $\mathrm{NO}_{2}$ was about 0.5 . During the winter of 1994-5, the correlations were lower than these between all air pollutants. There were no clear differences in correlations between urban and non-urban areas. Air pollutants and temperature were moderately highly correlated, whereas low correlations were found between air pollutants and the potential confounders day of study and incidence of influenza-like illness.

Table 4 shows the associations between indices of air pollution and the prevalence of $>10 \%$ decrements in evening PEF, respiratory symp- toms, and use of bronchodilators in children with symptoms. In the urban areas, the prevalence of $>10 \%$ decrements in evening PEF, LRS, and use of bronchodilators was positively associated with $\mathrm{PM}_{10}$, BS, and sulphate. Many associations reached significance. Also, $\mathrm{SO}_{2}$ was positively associated with those indicators of respiratory health but less consistently than the particulate pollutants. $\mathrm{NO}_{2}$ was positively associated with use of bronchodilators but not with LRS or $>10 \%$ decrements in evening PEF. No associations were found between indices of air pollution and the prevalence of URS and cough. Also, no associations were found between phlegm and the prevalence of $>10 \%$ decrements in morning PEF (not shown).

In the non-urban areas, associations between particle concentrations and $>10 \%$ decrements in evening PEF and LRS were in the same direction as in the urban areas, but significant associations were reached less often. As opposed to what was found in the urban areas, particle concentrations were not consistently associated with use of bronchodilators. However, the differences in effect estimates between urban and non-urban groups were generally small and the 95\% confidence intervals (95\% CIs) showed considerable overlap. There was essentially no association between $\mathrm{SO}_{2}$ and $\mathrm{NO}_{2}$ in the non-urban areas. The prevalence of $>10 \%$ decrements in morning PEF showed a consistent positive association with $\mathrm{PM}_{10}$ and BS (not shown in table 5). Significant associations were found with lag 2 and 5 day mean concentrations, and for BS also with previous day concentration. For example, ORs for lag 2 of $\mathrm{PM}_{10}$ and BS were 1.23 (95\% CI 1.01 to $1.50)$ and 1.26 (95\% CI 1.06 to 1.49$)$, respectively.

Both in the urban and the non-urban areas, 5 day mean concentrations seemed to be more closely related to respiratory health indicators than present day or lagged exposure variables.

Separate analyses for children who did and did not use medication were conducted to evaluate differences in response to air pollution. For this purpose, children were divided into those who did or did not report use of bronchodilators or maintenance medication during the study period. Table 5 presents the associations between $\mathrm{PM}_{10}$ concentrations and evening PEF, LRS, and use of bronchodilators after stratification for use of medication. It shows that in the urban panels, $\mathrm{PM}_{10}$ is strongly associated with LRS in the children who used 


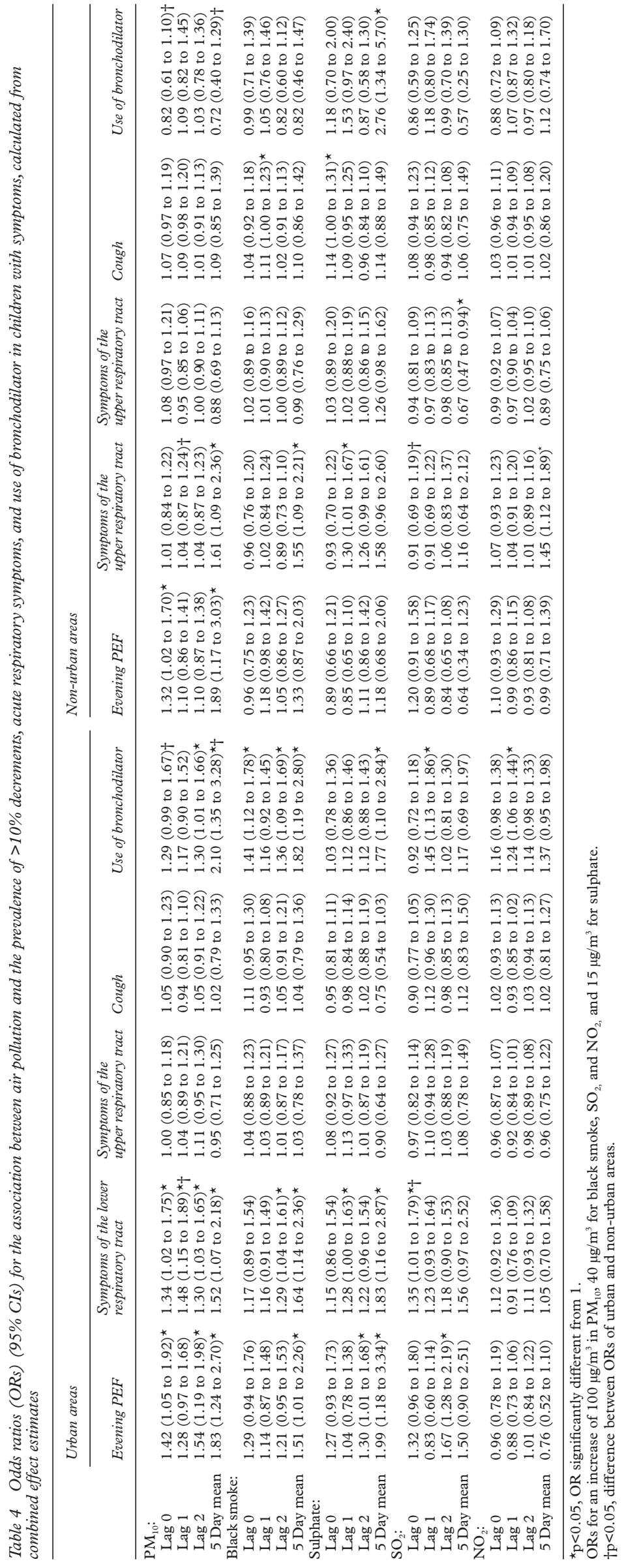

medication, but not in the children who did not use medication. Conversely, the association between $\mathrm{PM}_{10}$ and decrements in evening PEF is not more pronounced in children who used medication. Children who used medication reported significantly more LRS and use of bronchodilators with increasing $\mathrm{PM}_{10}$ concentration in the urban areas, but not in the non-urban areas. Although results are only presented for $\mathrm{PM}_{10}$, similar results were found for $\mathrm{BS}$ and to a lesser extent for $\mathrm{SO}_{2}$.

The associations between indices of air pollution and indicators of respiratory health in children without symptoms are presented in table 6 . In both the urban and non-urban areas, indices of air pollution were positively associated with the prevalence of $>10 \%$ decrements in evening PEF. The most consistent associations were found for $\mathrm{PM}_{10}$ and BS. Positive associations were also found between indices of air pollution and the prevalence of $>10 \%$ decrements in morning PEF in the urban areas, but not in the non-urban areas (not shown). No associations were found between indices of air pollution and the prevalence of cough, phlegm, and URS in the urban areas. In the non-urban areas, there was an unexpected tendency towards associations in the direction of lower prevalence of cough with higher concentrations of air pollution for all pollutants except sulphate. There were no significant differences between the ORs in urban and non-urban areas. By contrast with the findings among the children with symptoms, significant associations among the children without symptoms were mainly found at 0 and 1 day lags, and not with the 5 day means as exposure variables. In the panels without symptoms, the prevalence of LRS was so low that analyses resulted in extreme effect estimates and SEMs in all winters except 1993-4, when the mean prevalence was relatively high. The combined effect estimates for the three winters were (nearly) identical to the panel specific effect estimates for the winter of 1993-4, as the other winters hardly contributed to the weighting. Therefore, the associations with LRS are not presented in the tables. However, in the winter of 1993-4, a generally positive correlation between particle indices and respiratory health was found, especially in the non-urban panel where the effect estimates were more stable due to the higher prevalence. For example, the effect estimates for LRS in association with $\mathrm{PM}_{10}$ (lag 1) were 1.44 (95\% CI 0.54 to 3.83$)$ in the urban area and $1.58(95 \% \mathrm{CI}$ 1.06 to 2.35 ) in the non-urban area.

The association between nitrate concentration and respiratory health was also analysed. However, due to the high correlation with sulphate $(R$ between 0.75 and 0.87 ) the effect estimates for nitrate were nearly identical to those for sulphate, and therefore, the results are not presented. Sulphate was chosen to serve as an indicator for secondary aerosols, representing particles that mainly result from long distance transport.

Table 7 presents the associations between indices of air pollution and selected respiratory health indicators in children with symptoms in urban areas, calculated from two pollutant models. In two pollutant models where $\mathrm{PM}_{10}$ and $\mathrm{SO}_{2}$ 
Table 5 Odds ratios (ORs) (95\% CIs) for the association between air pollution and the prevalence of $>10 \%$ decrements in evening PEF, acute respiratory symptoms, and use of bronchodilators in children with symptoms with and without medication, calculated from combined effect estimates

\begin{tabular}{|c|c|c|c|c|c|c|}
\hline & \multicolumn{3}{|l|}{ Urban areas } & \multicolumn{3}{|l|}{ Non-urban areas } \\
\hline & Evening PEF & $L R S$ & Use of bronchodilator & Evening PEF & $L R S$ & Use of bronchodilator \\
\hline \multicolumn{7}{|c|}{$\begin{array}{l}\text { Children with medication, } \mathrm{PM}_{10} \text { : } \\
\mathrm{n}=34\end{array}$} \\
\hline Lag 0 & $1.37(0.81$ to 2.31$)$ & $1.80(1.17 \text { to } 2.75)^{\star}$ & $1.44(1.07 \text { to } 1.93)^{\star}$ & $1.45(0.93$ to 2.25$)$ & $0.96(0.76$ to 1.22$)$ & $0.83(0.59$ to 1.17$)$ \\
\hline $\mathrm{Lag} 1$ & $1.41(0.86$ to 2.32$)$ & $2.09(1.43 \text { to } 3.07)^{\star}$ & $1.30(0.97$ to 1.74$)$ & $1.37(0.94$ to 1.99$)$ & $1.09(0.87$ to 1.37$)$ & $1.04(0.75$ to 1.45$)$ \\
\hline Lag 2 & $1.40(0.87$ to 2.26$)$ & $1.72(1.19 \text { to } 2.50)^{\star}$ & $1.37(1.02 \text { to } 1.83)^{\star}$ & $1.33(0.92$ to 1.91$)$ & $1.04(0.83$ to 1.31$)$ & $1.07(0.78$ to 1.46$)$ \\
\hline 5 Day mean & $1.41(0.68$ to 2.94$)$ & $2.67(1.52 \text { to } 4.70)^{\star}$ & $2.25(1.34 \text { to } 3.79)^{\star}$ & $2.25(1.05 \text { to } 4.81)^{\star}$ & $1.24(0.76$ to 2.02$)$ & $0.75(0.38$ to 1.50$)$ \\
\hline \multicolumn{7}{|c|}{$\begin{array}{l}\text { Children without medication, } \mathrm{PM}_{10} \text { : } \\
\mathrm{n}=107\end{array}$} \\
\hline Lag 0 & $1.36(0.92$ to 2.00$)$ & $1.09(0.76$ to 1.56$)$ & - & $1.20(0.88$ to 1.64$)$ & $0.94(0.68$ to 1.30$)$ & - \\
\hline Lag 1 & $1.23(0.86$ to 1.75$)$ & $1.15(0.80$ to 1.63$)$ & - & $1.00(0.76$ to 1.32$)$ & $0.78(0.57$ to 1.08$)$ & - \\
\hline Lag 2 & $1.55(1.12 \text { to } 2.13)^{\star}$ & $1.31(0.94$ to 1.83$)$ & - & $1.04(0.80$ to 1.36$)$ & $0.93(0.69$ to 1.24$)$ & - \\
\hline 5 Day mean & $2.00(1.15 \text { to } 3.47)^{\star}$ & $1.24(0.76$ to 2.04$)$ & - & $1.90(1.10 \text { to } 3.30)^{\star}$ & $3.70(1.84 \text { to } 7.44)^{\star}$ & - \\
\hline
\end{tabular}

${ }^{\star} \mathrm{p}<0.05$, OR significantly different from 1 .

ORs for an increase of $100 \mu \mathrm{g} / \mathrm{m}^{3}$ in $\mathrm{PM}_{10}, 40 \mu \mathrm{g} / \mathrm{m}^{3}$ for black smoke, $\mathrm{SO}_{2}$, and $\mathrm{NO}_{2}$, and $15 \mu \mathrm{g} / \mathrm{m}^{3}$ for sulphate.

Table 6 Odds ratios (ORs) (95\% CIs) for the association between air pollution and the prevalence of $>10 \%$ decrements in evening PEF, acute respiratory symptoms, and use of bronchodilators in children without symptoms, calculated from combined effect estimates

\begin{tabular}{|c|c|c|c|c|c|c|}
\hline & \multicolumn{3}{|l|}{ Urban areas } & \multicolumn{3}{|l|}{ Non-urban areas } \\
\hline & Evening PEF & URS & Cough & Evening PEF & URS & Cough \\
\hline \multicolumn{7}{|l|}{$\mathrm{PM}_{10}:$} \\
\hline Lag 0 & $1.32(1.04 \text { to } 1.67)^{\star}$ & $1.07(0.87$ to 1.31$)$ & $1.09(0.90$ to 1.31$)$ & $1.40(1.09 \text { to } 1.80)^{\star}$ & $1.13(1.00$ to 1.28$)$ & $1.00(0.91$ to 1.11$)$ \\
\hline Lag 1 & $1.06(0.84$ to 1.34$)$ & $1.08(0.88$ to 1.32$)$ & $0.92(0.76$ to 1.11$)$ & $1.30(1.03 \text { to } 1.64)^{\star}$ & 0.95 (0.83 to 1.08$)$ & $0.88(0.80 \text { to } 0.97)^{\star}$ \\
\hline Lag 2 & $1.15(0.93$ to 1.42$)$ & $0.97(0.80$ to 1.19$)$ & $0.94(0.79$ to 1.13$)$ & $1.14(0.90$ to 1.44$)$ & $0.87(0.77 \text { to } 0.99)^{\star}$ & $0.95(0.86$ to 1.04$)$ \\
\hline 5 Day mean & $1.27(0.93$ to 1.74$)$ & $1.06(0.71$ to 1.59$)$ & $0.90(0.64$ to 1.27$)$ & 1.41 (0.93 to 2.14$)$ & $0.86(0.63$ to 1.17$)$ & $0.96(0.81$ to 1.14$)$ \\
\hline \multicolumn{7}{|l|}{ Black smoke: } \\
\hline Lag 0 & $1.45(1.12 \text { to } 1.87)^{\star}$ & 1.09 (0.88 to 1.36$)$ & $0.92(0.75$ to 1.12$)$ & $1.60(1.29 \text { to } 2.00)^{\star}$ & $1.04(0.90$ to 1.20$)$ & $0.94(0.84$ to 1.05$)$ \\
\hline Lag 1 & $1.13(0.90$ to 1.43$)$ & $1.17(0.96$ to 1.43$)$ & $1.06(0.88$ to 1.27$)$ & $0.92(0.76$ to 1.12$)$ & $0.98(0.86$ to 1.12$)$ & $0.90(0.82 \text { to } 0.99)^{\star}$ \\
\hline Lag 2 & $1.26(1.03 \text { to } 1.54)^{\star}$ & $0.91(0.74$ to 1.11$)$ & $1.05(0.88$ to 1.25$)$ & $1.14(0.94$ to 1.38$)$ & 0.90 (0.79 to 1.03$)$ & $0.92(0.83$ to 1.01$)$ \\
\hline 5-day mean & $1.42(1.01 \text { to } 1.99)^{\star}$ & $1.18(0.78$ to 1.80$)$ & $0.99(0.71$ to 1.38$)$ & $1.14(0.80$ to 1.76$)$ & $0.92(0.67$ to 1.24$)$ & $0.87(0.74$ to 1.03$)$ \\
\hline \multicolumn{7}{|l|}{ Sulphate: } \\
\hline Lag 0 & 1.15 (0.87 to 1.51$)$ & $1.21(0.97$ to 1.51$)$ & $1.09(0.89$ to 1.34$)$ & $1.33(0.95$ to 1.86$)$ & $1.09(0.90$ to 1.32$)$ & $1.17(1.01 \text { to } 1.35)^{\star}$ \\
\hline Lag 1 & $1.11(0.86$ to 1.44$)$ & $0.97(0.79$ to 1.19$)$ & $0.87(0.71$ to 1.07$)$ & $0.93(0.69$ to 1.24$)$ & $0.96(0.79$ to 1.15$)$ & $1.05(0.90$ to 1.23$)$ \\
\hline Lag 2 & $1.10(0.86$ to 1.40$)$ & $1.06(0.85$ to 1.30$)$ & $1.10(0.90$ to 1.33$)$ & $1.19(0.92$ to 1.55$)$ & $0.96(0.80$ to 1.14$)$ & $0.95(0.83$ to 1.10$)$ \\
\hline 5 Day mean & $1.29(0.87$ to 2.15$)$ & $1.23(0.75$ to 2.01$)$ & $0.81(0.52$ to 1.26$)$ & $1.35(0.63$ to 2.88$)$ & $1.34(0.98$ to 1.84$)$ & $1.15(0.86$ to 1.53$)$ \\
\hline \multicolumn{7}{|l|}{$\mathrm{SO}_{2}:$} \\
\hline Lag 0 & $1.13(0.88$ to 1.47$)$ & $0.92(0.76$ to 1.11$)$ & 0.93 (0.78 to & $1.10(0.87$ to 1.39$)$ & $1.07(0.92$ to 1 & $0.86(0.76 \text { to } 0.97)^{\star}$ \\
\hline Lag 1 & $1.16(0.90$ to 1.50$)$ & $1.10(0.91$ to 1.34$)$ & $1.02(0.84$ to 1.23$)$ & $1.07(0.85$ to 1.35$)$ & $0.85(0.72$ to 1.00$)$ & 0.95 (0.83 to 1.08$)$ \\
\hline Lag 2 & $1.10(0.87$ to 1.39$)$ & $0.83(0.70 \text { to } 0.99)^{\star}$ & $0.97(0.83$ to 1.15$)$ & $1.10(0.88$ to 1.38$)$ & $0.94(0.80$ to 1.10$)$ & $0.94(0.82$ to 1.06$)$ \\
\hline 5 Day mean & $1.33(0.89$ to 2.00$)$ & $0.66(0.42$ to 1.03$)$ & $1.04(0.69$ to 1.57$)$ & $1.14(0.66$ to 1.96$)$ & $0.78(0.52$ to 1.18$)$ & $0.87(0.68$ to 1.12$)$ \\
\hline \multicolumn{7}{|c|}{ (1.07 } \\
\hline Lag 0 & 1.13 (0.94 to 1.35$)$ & $1.05(0.92$ to 1.20$)$ & $1.02(0.89$ to 1.17$)$ & $1.14(0.98$ to 1.33$)$ & 1.03 (0.94 to 1.13 ) & $0.93(0.87$ to 1.00$)$ \\
\hline Lag 1 & $1.14(0.97$ to 1.34$)$ & $0.97(0.86$ to 1.11$)$ & $0.91(0.81$ to 1.04$)$ & $1.08(0.94$ to 1.25$)$ & 0.97 (0.89 to 1.07$)$ & $0.90(0.84 \text { to } 0.97)^{\star}$ \\
\hline Lag 2 & $1.05(0.89$ to 1.23$)$ & $0.95(0.84$ to 1.08$)$ & $1.01(0.89$ to 1.14$)$ & $0.99(0.85$ to 1.15$)$ & $1.01(0.92$ to 1.09$)$ & $0.96(0.90$ to 1.03$)$ \\
\hline 5 Day mean & $1.17(0.84$ to 1.63$)$ & $1.08(0.75$ to 1.56$)$ & 1.05 (0.74 to 1.48$)$ & $1.21(0.89$ to 1.63$)$ & $0.98(0.80$ to 1.21$)$ & $0.93(0.82$ to 1.05$)$ \\
\hline
\end{tabular}

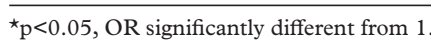

ORs for an increase of $100 \mu \mathrm{g} / \mathrm{m}^{3}$ in $\mathrm{PM}_{10}, 40 \mu \mathrm{g} / \mathrm{m}^{3}$ for black smoke, $\mathrm{SO}_{2}$, and $\mathrm{NO}_{2}$, and $15 \mu \mathrm{g} / \mathrm{m}^{3}$ for sulphate.

Table 7 Odds ratios (ORs) (95\% CIs) for the association between air pollution and the prevalence of $>10 \%$ decrements in evening PEF, acute respiratory symptoms, and use of bronchodilators in children with symptoms from the urban area, calculated from combined effect estimates obtained in two pollutant models

\begin{tabular}{|c|c|c|c|c|c|c|c|}
\hline & \multicolumn{3}{|l|}{ First pollutant } & & \multicolumn{3}{|l|}{ Second pollutant } \\
\hline & Evening PEF & $\begin{array}{l}\text { Symptoms of the lower } \\
\text { respiratory tract }\end{array}$ & Use of bronchodilator & & Evening PEF & $\begin{array}{l}\text { Symptoms of the lower } \\
\text { respiratory tract }\end{array}$ & $\begin{array}{l}\text { Use of } \\
\text { bronchodilator }\end{array}$ \\
\hline $\mathrm{PM}_{10}$ : & & & & $\mathrm{SO}_{2}$ : & & & \\
\hline Lag 0 & 1.33 (0.95 to 1.87$)$ & $1.24(0.91$ to 1.68$)$ & $1.29(0.97$ to 1.71$)$ & Lag 0 & $1.14(0.80$ to 1.61$)$ & $1.29(0.94$ to 1.76$)$ & $0.95(0.72$ to 1.25$)$ \\
\hline Lag 1 & $1.45(1.05 \text { to } 2.01)^{\star}$ & $1.48(1.10 \text { to } 1.99)^{\star}$ & $0.84(0.62$ to 1.15$)$ & Lag 1 & $0.75(0.51$ to 1.09$)$ & $1.04(0.75$ to 1.46$)$ & $1.71(1.26 \text { to } 2.32)^{\star}$ \\
\hline Lag 2 & $1.22(0.89$ to 1.67$)$ & $1.27(0.95$ to 1.71$)$ & $1.29(0.96$ to 1.74$)$ & Lag 2 & $1.56(1.13 \text { to } 2.13)^{\star}$ & $1.05(0.77$ to 1.43$)$ & $0.94(0.70$ to 1.28$)$ \\
\hline 5 Day mean & $1.81(1.04 \text { to } 3.16)^{\star}$ & $1.46(0.89$ to 2.42$)$ & $1.84(1.06 \text { to } 3.19)^{\star}$ & 5 Day mean & $1.03(0.50$ to 2.10$)$ & $1.13(0.60$ to 2.13$)$ & $0.76(0.45$ to 1.30$)$ \\
\hline $\mathrm{PM}_{10}$ : & & & & Black smoke: & & & \\
\hline Lag 0 & $1.28(0.85$ to 1.93$)$ & $1.51(1.04 \text { to } 2.18)^{\star}$ & $1.16(0.86$ to 1.57$)$ & Lag 0 & $1.04(0.71$ to 1.55$)$ & $0.94(0.65$ to 1.36$)$ & $1.31(0.98$ to 1.75$)$ \\
\hline Lag 1 & $1.03(0.69$ to 1.56$)$ & $1.86(1.30 \text { to } 2.67)^{\star}$ & $1.33(1.00 \text { to } 1.76)^{\star}$ & Lag 1 & $1.04(0.72$ to 1.50$)$ & $0.76(0.54$ to 1.07$)$ & $1.05(0.79$ to 1.38$)$ \\
\hline Lag 2 & $1.59(1.07 \text { to } 2.35)^{\star}$ & $1.22(0.84$ to 1.78$)$ & $1.00(0.74$ to 1.34$)$ & Lag 2 & $0.85(0.60$ to 1.20$)$ & $1.14(0.82$ to 1.57$)$ & $1.34(1.03 \text { to } 1.76)^{\star}$ \\
\hline 5 Day mean & $0.74(0.27$ to 2.05$)$ & $1.80(0.68$ to 4.77$)$ & $2.49(0.80$ to 7.81$)$ & 5 Day mean & $0.86(0.37$ to 1.86$)$ & $1.07(0.47$ to 2.42$)$ & $1.45(0.58$ to 3.64$)$ \\
\hline $\mathrm{PM}_{10}$ : & & & & Sulphate: & & & \\
\hline Lag 0 & $1.39(0.92$ to 2.09$)$ & $1.61(1.08 \text { to } 2.40)^{\star}$ & $1.59(1.13 \text { to } 2.24)^{\star}$ & Lag 0 & $1.06(0.73$ to 1.55$)$ & to 1.25$)$ & $0.77(0.55$ to 1.06$)$ \\
\hline Lag 1 & $1.22(0.78$ to 1.88$)$ & $1.42(0.98$ to 2.07$)$ & $1.05(0.74$ to 1.49$)$ & Lag 1 & 0.97 (0.66 to 1.42$)$ & $1.02(0.78$ to 1.42$)$ & $1.11(0.79$ to 1.56$)$ \\
\hline Lag 2 & $1.32(0.88$ to 1.97$)$ & $1.24(0.87$ to 1.76$)$ & $1.27(0.91$ to 1.78$)$ & Lag 2 & $1.18(0.84$ to 1.67$)$ & $1.07(0.78$ to 1.47$)$ & $1.05(0.76$ to 1.44$)$ \\
\hline 5 Day mean & $1.11(0.53$ to 2.32$)$ & $1.76(0.95$ to 3.28$)$ & $2.21(1.21 \text { to } 4.05)^{\star}$ & 5 Day mean & $1.58(0.73$ to 3.40$)$ & 1.21 (0.62 to 2.37$)$ & $0.95(0.50$ to 1.79$)$ \\
\hline Black smoke: & & & & Sulphate: & & & \\
\hline Lag 0 & 1.23 & to 1.72 ) & o 2.09$)^{\star}$ & Lag 0 & 1. & 1.0 & $1.20)$ \\
\hline Lag 1 & $1.10(0.77$ to 1.58$)$ & $0.91(0.65$ to 1.27$)$ & $1.17(0.88$ to 1.56$)$ & Lag 1 & $1.03(0.71$ to 1.49$)$ & $1.32(0.95$ to 1.84$)$ & $1.04(0.78$ to 1.40$)$ \\
\hline $\mathrm{Lag} 2$ & $0.94(0.67$ to 1.31$)$ & $1.17(0.86$ to 1.58$)$ & $1.32(1.00 \text { to } 1.73)^{\star}$ & $\mathrm{Lag} 2$ & $1.37(0.95$ to 1.96$)$ & $1.09(0.79$ to 1.50$)$ & $0.93(0.71$ to 1.23$)$ \\
\hline 5 Day mean & $1.02(0.49$ to 2.10$)$ & $1.47(0.82$ to 2.62$)$ & $1.82(0.90$ to 3.68$)$ & 5 Day mean & $1.96(0.82$ to 4.70$)$ & $1.23(0.62$ to 2.45$)$ & $1.10(0.50$ to 2.41$)$ \\
\hline
\end{tabular}

${ }^{\star} \mathrm{p}<0.05$, OR significantly different from 1 .

ORs for an increase of $100 \mu \mathrm{g} / \mathrm{m}^{3}$ in $\mathrm{PM}_{10}, 40 \mu \mathrm{g} / \mathrm{m}^{3}$ for black smoke, and $\mathrm{SO}_{2}$, and $15 \mu \mathrm{g} / \mathrm{m}^{3}$ for sulphate. 
were included simultaneously, an independent effect of $\mathrm{PM}_{10}$ remained whereas no consistent pattern was found for $\mathrm{SO}_{2}$. In models of $\mathrm{PM}_{10}$ with BS, and of $\mathrm{PM}_{10}$ with sulphate, the $\mathrm{PM}_{10}$ effects generally remained, whereas the estimates for BS and sulphate often became non-significant. In models of BS with sulphate no consistent pattern emerged. Two pollutant models in the panels with symptoms from the non-urban areas also indicated that the associations with $\mathrm{PM}_{10}$ were most consistent (not shown), but the patterns were less clear than for the urban panels, as less consistently positive assocations were found in the one pollutant models.

The associations with 5 day mean concentrations generally became less consistent in the two pollutant models, probably because of the high correlation among these variables.

\section{Discussion}

In this study, we have found that in children with symptoms who live in urban areas, the daily prevalence of LRS, use of bronchodilators, and decrements in evening PEF had a consistent positive association with the concentration of $\mathrm{PM}_{10}$, BS, and sulphate. There was also a positive association with $\mathrm{SO}_{2}$, but not with $\mathrm{NO}_{2}$. After stratification for use of medication, the prevalence of LRS was strongly associated with particle concentrations in children who used medication, but not in children who did not. In two pollutant models, when indicators of particulate air pollution $\left(\mathrm{PM}_{10}\right.$, $\mathrm{BS}$, and sulphate) and $\mathrm{SO}_{2}$ were evaluated simultaneously, independent effects were found more consistently for particles than for $\mathrm{SO}_{2}$. In children with symptoms who lived in non-urban areas weaker and less consistent positive associations were found with indicators of particulate air pollution. No associations with the gaseous pollutants $\mathrm{SO}_{2}$ and $\mathrm{NO}_{2}$ were found. In children without symptoms, the daily prevalence of decrements in PEF was positively correlated with $\mathrm{PM}_{10}$ and $\mathrm{BS}$ in both the urban and non-urban areas. The prevalence of URS, cough, and phlegm was not associated with air pollution in any of the subgroups.

In a review article, Dockery and Pope ${ }^{3}$ combined the results of the then available panel studies from the United States and Europe, and calculated that an increase in $\mathrm{PM}_{10}$ concentration of $100 \mu \mathrm{g} / \mathrm{m}^{3}$ was associated with increases in the prevalence of LRS and use of bronchodilators of $30 \%$ and $29 \%$, respectively. Although the definition of LRS was not exactly the same as in our study, these effect estimates correspond well with the ones from our study; we found that for children with symptoms in the urban area an increase in same day $\mathrm{PM}_{10}$ concentration was associated with an increase of $34 \%$ and $29 \%$ in the prevalence of LRS and use of bronchodilators, respectively. For URS and cough, smaller increases of $7 \%$ and $12 \%$ were reported by Dockery and Pope. ${ }^{3}$ Thus, our study is in agreement with earlier panel studies as larger relative increases were found for LRS and use of bronchodilators than for URS and cough.
Both in the urban and non-urban panels with symptoms, 5 day mean concentrations seemed to be more related to indicators of respiratory health than present day or lagged exposure variables. This is in line with other studies $^{1416}$ and suggests that changes in respiratory status might reflect cumulative exposure of several days before the measurement.

Although the children who used medication in the urban areas increased their use of bronchodilators in association with increased particle concentrations, the strongest increase in LRS was found in this subgroup. Apparently, increased use of bronchodilators did not prevent the adverse effects of particles on respiratory health. This is in agreement with the results of stratified analyses based on use of medication in a panel study of mildly asthmatic children in Sokolov, Czech Republic. ${ }^{17}$ Children who used medication increased their use of $\beta$ agonists in association with increased particle concentrations, but this did not prevent adverse effects on other health outcomes (in that case decreases in PEF and increases in the prevalence of cough). ${ }^{17}$ The authors speculated that this was a result of inadequate supplies of medication for asthma in the Czech Republic. In The Netherlands, however, this is not a plausible explanation. Apparently, use of medication does not prevent the adverse effects of particulate air pollution in asthmatic children, as was suggested in other studies. ${ }^{1328}$

Compared with other panel studies, a different approach was used to analyse PEF data, focusing not on decrements in population average PEF but on the fraction of children experiencing substantial decrements in PEF. In a reanalysis of data from seven panels including school children with and without symptoms, Hoek et $a l^{15}$ have compared the two approaches. It was shown that an increase of 10 $\mu \mathrm{g} / \mathrm{m}^{3}$ of the same day $\mathrm{PM}_{10}$ concentration was associated with a decrement in the population mean PEF of $0.07 \%$. A significant increase of the prevalence of $>10 \%$ decrements in PEF of $2.7 \%$ was associated with the same exposure. For an increase of $100 \mu \mathrm{g} / \mathrm{m}^{3}$ this corresponds to an OR of 1.31 , a value very similar to the ORs found in our study. An advantage of the approach proposed by Hoek et $a l^{15}$ is that, as in symptom analysis, it provides effect estimates that focus on the fraction of the population experiencing a specific (adverse) response.

Can some sort of bias have caused the associations between particle concentration and respiratory health found in our study? It is unlikely that selection processes could have caused bias in this time series study because each child served as its own control. Bias due to the low response may have occurred in the unlikely case that within the subgroup of children with and without (chronic respiratory) symptoms, response was associated with susceptibility to winter air pollution.

Observer bias in reporting symptoms might have occurred when parents of the children were informed by the mass media about episodes of air pollution. However, during the study period all concentrations of air pollutants were below the limits used in the Dutch smog 
alert system, and no warnings were issued. Potential confounders that might bias the association between air pollution and respiratory health in time series studies are meteorological variables (mainly ambient temperature), respiratory infections, and long term time trends. All associations were adjusted for ambient temperature and for non-linear long term time trends (generally in the order of weeks) in the prevalence of symptoms, use of bronchodilators, and decrements in PEF. The adjustment for time trends was more detailed than in previous panel studies, which either specified no time trend or a linear trend. The incidence of influenza-like illness in the general population, registered by a sentinel system of general practitioners, was used to adjust for the potential confounding effect of respiratory infections. In previous panel studies, no adjustments for the potential confounding effect of respiratory infections were made. We will report in a separate paper (unpublished data) that the incidence of influenza-like illness in the general population was associated with respiratory health in selected groups.

In our study, effects on PEF were somewhat larger for children with than without symptoms. In a previous Dutch study in school children, the association between particulate air pollution and lung function was reported to be similar in children with and without chronic respiratory symptoms. ${ }^{7}$ By contrast, Neas et $a l^{18}$ found that children without chronic respiratory symptoms seemed to be less susceptible to the effects of air pollution on PEF than were children with symptoms. Pope and Dockery ${ }^{14}$ found effects on PEF in both children with and without symptoms, but in children with symptoms stronger associations were found.

In our study, indices of air pollution were not associated with respiratory symptoms in the panels without symptoms, whereas in panels with symptoms an association with LRS and use of bronchodilators was found. However, both LRS and use of bronchodilators were never or rarely reported in the panels without symptoms. The finding that indices of air pollution were not associated with respiratory symptoms in the groups without symptoms is in agreement with other studies. In two Dutch studies ${ }^{6}$ no association between particulate air pollution and respiratory symptoms was found in mainly healthy school children. Pope and Dockery $^{14}$ reported positive associations between $\mathrm{PM}_{10}$ and the prevalence of URS, LRS, and cough in both panels with and without symptoms, but the associations were weaker, and generally non-significant, in the panels without symptoms. LRS could be analysed in the group without symptoms ${ }^{14}$ because the definition was different from ours (trouble breathing, wheeze, and dry cough instead of shortness of breath, wheeze, asthma attacks).

Thus, children without symptoms seem less susceptible to the acute effects of air pollution than children with symptoms because these do not develop the asthmatic symptoms that are most affected by increasing levels of air pollution.
It cannot easily be concluded from the one pollutant models which indicator for air pollution $\left(\mathrm{PM}_{10}, \mathrm{BS}\right.$, sulphate, or $\left.\mathrm{SO}_{2}\right)$ was most consistently associated with respiratory health in the groups, although the associations with sulphate were less consistent in the panels without symptoms. Therefore, two pollutant models evaluating two indicators of air pollution simultaneously were specified for the panels with symptoms in an attempt to separate effects from specific components. The concentrations of $\mathrm{PM}_{10}, \mathrm{BS}$, sulphate, and $\mathrm{SO}_{2}$ were intercorrelated, as meteorology is a dominating factor in determining day to day variations in concentrations of air pollution. However, as indicated by the SEMs associated with the regression coefficients, this did not lead to collinearity problems. The two pollutant models indicated that $\mathrm{SO}_{2}$ was less consistently associated with respiratory health than indicators for particulate air pollution, which was expected given the low $\mathrm{SO}_{2}$ concentrations that were found in our study. They also indicated that in panels with symptoms in the urban areas, $\mathrm{PM}_{10}$ was more consistently associated with health outcomes than BS and sulphate. Black smoke can be considered as an indicator of fine black particles (elemental carbon) emitted by diesel engines which is generally found in the fine particle fraction. Sulphate is also present in the fine fraction and serves as an indicator of secondary aerosols, representing particles that mainly result from long range transport. The finding that the most consistent assocations were found with $\mathrm{PM}_{10}$ contrasts with two previous time series studies performed in Amsterdam which found that BS was more strongly associated with health outcomes than $\mathrm{PM}_{10}{ }^{16}{ }^{19}$

In children with symptoms, $\mathrm{PM}_{10}$ and $\mathrm{BS}$ concentrations were more strongly and consistently associated with use of bronchodilators, and to a lesser extent LRS, in the urban areas than in the non-urban areas. After stratification by use of medication it was shown that the differences in response between urban and non-urban groups were restricted to the children who used medication. We cannot rule out that differences in use of maintenance medication are responsible for this. Calculated over the three winters, the mean prevalence of maintenance medication was almost twofold lower in the urban areas $(8.5 \%)$ than in the non-urban areas $(15.5 \%)$. As a result, children in the urban areas might have to rely more on bronchodilators during periods with high air pollution than children in the non-urban areas. Separate analyses for children who used only bronchodilators during the study period, and for children who used both bronchodilators and maintenance medication could show if use of maintenance medication diminishes the response to air pollution, but the number of children that used bronchodilators only was too small for a meaningful analysis. Moreover, in such an analysis the amount of maintenance use of medication by each child during the study period should be taken in account. The percentage of the children who used medication that ever reported use of maintenance 
medication did not differ between urban and non-urban panels $(76.5 \%$ and $78.7 \%$, respectively), but children in the non-urban areas obviously took their maintenance medication more often, given the higher prevalence. Thus, we cannot conclude that the tendency for stronger effects of particles on LRS and especially use of bronchodilators in the urban areas reflects a more toxic air pollution mixture in the urban area, as we cannot exclude the possibility that differences in use of medication are responsible for this. Moreover, in the panels without symptoms no tendency of stronger associations in the urban areas was found. The results of our study are to some extent at variance with the results of the PEACE study; in 14 urban and 14 non-urban groups with symptoms, including the 1993-4 groups of our study, generally no clear effects of air pollutants on PEF, respiratory symptoms, or use of bronchodilators were found in the urban and non-urban panels. ${ }^{20}$ The main difference between the two studies is that in the Dutch studies, we were able to combine findings from three different winter periods whereas in the PEACE study, the observation period was about 2 months in one winter only. The Dutch studies may therefore have been less vulnerable to the effect of unmeasured events during that particular period. Another difference is that we were able to control at least to some extent for the role of respiratory infections through the data from the sentinel system of general practitioners on influenza-like illness.

In this study, exposure assessment was based on fixed site ambient air concentrations measured at one location in both areas. In the urban areas, a background location was selected instead of a site more directly influenced by traffic emissions, because the measurement site needed to be representative for other locations in the study area. It might be questioned whether exposure to air pollution was adequately characterised by fixed site ambient air concentrations only. However, the resulting misclassification would probably result in a downward bias of the association found between air pollution and health end points. Recent studies in The Netherlands ${ }^{29} 30$ have shown that the time series correlation between ambient and personal $\mathrm{PM}_{10}$ was reasonably high. No consistent differences were found in the strength of the correlation between ambient and personal $\mathrm{PM}_{10}$ between children living in Amsterdam and children living in the non-industrial small town Wageningen. ${ }^{29}$

Transient decrements of $\mathrm{FVC}$ and $\mathrm{FEV}_{1}$ of $10 \%$ have been considered as the border between mild and moderate response. ${ }^{31}{ }^{32}$ The effect estimates found in our study indicate that in children with symptoms, an increase of $83 \%$ in the number of subjects with a PEF response of that magnitude was associated with an increase in 5 day mean $\mathrm{PM}_{10}$ concentration of $100 \mu \mathrm{g} / \mathrm{m}^{3}$. An increase of $52 \%$ was found for the prevalence of LRS in children with symptoms, whereas a twofold increase in use of bronchodilators was associated with a 100 $\mu \mathrm{g} / \mathrm{m}^{3}$ increase in 5 day mean $\mathrm{PM}_{10}$ concentra- tion. In children without symptoms in both urban and non-urban areas, particle effects on PEF were of smaller magnitude than for children with symptoms, and no associations with respiratory symptoms were found.

In conclusion, this study suggests that children with symptoms are more susceptible to particulate air pollution than children without symptoms, and that use of medication for asthma does not prevent the adverse effects of particulate air pollution.

1 World Health Organization. Air quality guidelines for Europe. Copenhagen: WHO regional publications, 1987. (European series no 23.)

2 Chow JC, Watson JG, Lowenthal DH, et al. $\mathrm{PM}_{10}$ and $\mathrm{PM}_{2.5}$ compositions in California's San Joaquin Valley. Fournal of Aerosol Science and Technology 1993;18:105-28.

3 Dockery DW, Pope CA III. Acute respiratory effects of particulate air pollution. Annu Rev Public Health 1994;15:10732.

4 Brunekreef B, Dockery DW, Kryzanowski M. Epidemiological studies on short-term effects of low levels of major ambient air pollution components. Environ Health Perspect 1995;103(Suppl s):3-13.

5 Roemer W, Hoek G, Brunekreef B. Effect of ambient winter air pollution on respiratory health of children with chronic respiratory symptoms. Am Rev Respir Dis 1993;147:11824 .

6 Hoek G, Brunekreef B. Acute effects of a winter air pollution episode on pulmonary function and respiratory ymptoms in children. Arch Environ Health 1993;48:32835.

7 Hoek G, Brunekreef B. Effects of low level winter air polluion concentrations on respiratory health of Dutch children. Environ Res 1994;64:136-50.

8 Florey C du V, Leeder SR. Methods for cohort studies of chronic airflow limitation. Copenhagen: WHO regional publications, 1982. (European series no 23.)

9 Roemer W, Hoek G, Brunekreef B, et al. Effect of short-term changes in urban air pollution on the respiratory health of children with chronic respiratory symptoms: the PEACE project. European Respiratory Reviews 1998;8:4-11,52.

project. European Respiratory Reviews $1998 ; 8: 4-11,52$.
10 Zee SC van der, Hoek G, Harssema H, et al. Characterization of particulate air pollution in urban and non-urban tion of particulate air pollution in urban and non-urban
areas in The Netherlands. Atmos Environ 1998;32:371729 .

11 Withdrawn.

12 SAS Institute. SAS/ETS user's guide, version 6. Cary, NC: SAS Institute, 1988

13 Pope CA III, Dockery DW, Spengler JD, et al. Respiratory health and $\mathrm{PM}_{10}$ pollution: a daily time series analysis. $\mathrm{Am}$ Rev Respir Dis 1991;144:668-74.

14 Pope CA III, Dockery DW. Acute health effects of $\mathrm{PM}_{10}$ pollution on symptomatic and asymptomatic children. Am Rev Respir Dis 1992;145:1123-8.

15 Hoek G, Dockery DW, Pope CA, et al. $\mathrm{PM}_{10}$ is associated with substantial increases of the prevalence of large peak flow decrements in children: a re-analysis of peak flow data of five panel studies. Eur Respir f 1998;11:1307-11.

16 Gielen MH, Zee SC van der, Wijnen JH van, et al. Acute effects of summer air pollution on respiratory health of asthmatic children. Am F Respir Crit Care Med 1997;155: asthmatic ch $2105-8$.

17 Peters A, Dockery DW, Heinrich J, et al. Medication use modifies the health effects of particulate sulfate air pollution in children with asthma. Environ Health Perspect 1997;105:430-5

18 Neas LM, Dockery DW, Koutrakis P, et al. The association of ambient air pollution with twice daily peak expiratory flow rate measurements in children. Am $\mathcal{F}$ Epidemiol 1995; 141:111-22.

19 Verhoeff AP, Hoek G, Schwartz J, et al. Air pollution and daily mortality in Amsterdam. Epidemiology 1996;7;22530.

20 Roemer W, Hoek G, Brunekreef B, et al. The PEACE project: general discussion.European Respiratory Reviews 1998;8:125-30.

21 Hildemann LM, GR Markowski, GR Cass. Chemical composition of emissions from urban sources of fine organic position of emissions from urban sources of

22 Seaton A, MacNee W, Donaldson K, et al. Particulate air pollution and acute health effects. Lancet 1995;345 176-8.

23 Peters A, Wichmann HE, Tuch T, et al. Respiratory effects are associated with the number of ultrafine particles. $A m \mathcal{F}$ Respir Crit Care Med 1997;155:1376-83.

24 Brunekreef B, Janssen NAH, Hartog J de, et al. Air pollution from truck traffic and lung function in children living near motorways. Epidemiology 1997;8:298-303.

25 Vliet $\mathrm{P}$ van, Knape M, Hartog J de, et al. Motor vehicle exhaust and chronic respiratory symptoms in children living near freeways. Environ Res 1997;74:122-32.

26 Pekkanen J, Timonen KL, Ruuskanen J, et al. Effects of ultrafine and fine particles in urban air on peak expiratory flow among children with asthmatic symptoms. Environ Res 1997;74:24-33. 
27 Dusseldorp A, Kruize H, Brunekreef B, et al. Acute effects of $\mathrm{PM}_{10}$ and airborne iron on respiratory health: a panel study among adults living near a steel industry in the Netherlands. Am $\mathcal{F}$ Respir Crit Care Med 1995;152:1932-9.

28 Silverman F, Hosein HR, Corey P, et al. Effects of particulate matter exposure and medication use on asthmatics. Arch Environ Health 1992;46:51-6.

29 Janssen NAH, Hoek G, Harssema H, et al. Childhood exposure to $\mathrm{PM}_{10}$ : a relation between personal, classroom, and outdoor concentrations. Occup Environ Med 1997;54
888-94.

30 Janssen NAH, Hoek G, Brunekreef B, et al. Personal sampling of particles in adults: relation among personal, indoor, and outdoor air concentrations. Am $\mathcal{F}$ Epidemiol 1998;147:537-47.

31 Lippmann $M$. Health significance of pulmonary function responses to airborne irritants. Fournal of the Air Pollution Control Association 1988;38:881-7.

32 World Health Organisation. Acute effects on health of smog episodes. Geneva: WHO regional publications, 1992. (European series no 4.)

\section{Occupational and Environmental Medicine - http://www.occenvmed.com}

Visitors to the world wide web can now access Occupational and Environmental Medicine either through the BMJ Publishing Group's home page (http://www.bmjpg.com) or directly by using its individual URL (http://www.occenvmed.com). There they will find the following:

- Current contents list for the journal

- Contents lists of previous issues

- Members of the editorial board

- Subscribers' information

- Instructions for authors

- Details of reprint services.

A hotlink gives access to:

- BMJ Publishing Group home page

- British Medical Association website

- Online books catalogue

- BMJ Publishing Group books.

The web site is at a preliminary stage and there are plans to develop it into a more sophisticated site. Suggestions from visitors about features they would like to see are welcomed. They can be left via the opening page of the BMJ Publishing Group site or, alternatively, via the journal page, through "about this site". 